\title{
A Cell Immobilized FOG-Trap System for Fat, Oil and Grease Removal from Restaurant Wastewater
}

Grace M. Nisola ${ }^{1}$, Eul Saeng Cho ${ }^{1}$, H.K. Shon ${ }^{3}$, Dan Tian ${ }^{4}$, Dong Jun Chun ${ }^{5}$, Eun Mi Gwon ${ }^{6}$, and Wook Jin Chung $^{7^{*}}$

1 These authors contributed equally to this work.

${ }^{1}$ Department of Environmental Engineering and Biotechnology at Myong-Ji University [Yongin, 449-728, Korea]. E-mail: cmgg8_ashley@yahoo.com

${ }^{1}$ Department of Environmental Engineering and Biotechnology at Myong-Ji University [Yongin, 449-728, Korea]. E-mail: escho1226@hotmail.com

${ }^{3}$ Faculty of Engineering, University of Technology, Sydney [P.O. Box 123, Broadway, NSW 2007, Australia]. E-mail: shonhokyong@yahoo.co.kr

${ }^{4}$ Department of Environmental Engineering and Biotechnology at Myong-Ji University [Yongin, 449-728, Korea]. E-mail: tongtongtian@hotmail.com

${ }^{5}$ Department of Environmental Engineering and Biotechnology at Myong-Ji University [Yongin, 449-728, Korea]. E-mail: chdj1000@hotmail.com

${ }^{6}$ Department of Environmental Engineering and Biotechnology at Myong-Ji University [Yongin, 449-728, Korea]. E-mail: emgwon0423@hotmail.com

$7^{7 *}$ Department of Environmental Engineering and Biotechnology at Myong-Ji University [Yongin, 449728, Korea]. To whom all correspondence should be addressed (Tel.: (82)-31-330-6687, Fax: (82)-31337-2902). E-mail: wjc0828@gmail.com. 


\section{ABSTRACT}

Cell immobilized lipase-producing bacteria on three different matrices were incorporated in a fat-,

oil- and grease (FOG) trap system for restaurant wastewater treatment. During a 16-day lab-scale experiment for the treatment of synthetic FOG wastewater containing soybean oil, no significant difference (two-tailed $t$-test at 95\% confidence interval) in the FOG removal between two systems was observed at FOG influent $\leq 1000 \mathrm{mg} / \mathrm{L}$. However, the typical trap showed lower FOG removal efficiency than the matrix-based system when the influent FOG concentration was increased to $\geq 5000 \mathrm{mg} / \mathrm{L}$. In addition, the matrix-based trap system was able to sustain a stable high FOG removal, with $<100 \mathrm{mg} / \mathrm{L}$ effluent, even at $10000 \mathrm{mg} / \mathrm{L}$ influent FOG. Based on FOG heights measured and mass balance calculations, 97.4- and $99.5 \%$ of the total FOG load for 16 days were removed in a typical trap and matrix-based system, respectively. About $93.6 \%$ of the removal in the matrix-based was accounted to biodegradation. The 30-day full-scale operations demonstrated a distinguishably better performance in the matrix-based system $(92.7 \pm 9.06 \%$ of $1044.8 \pm 537.27 \mathrm{mg}$ FOG/L) than in the typical trap system (74.6 $\pm 27.13 \%$ of $463.4 \pm 296.87 \mathrm{mg}$ FOG/L) for the treatment of barbeque restaurant wastewater.

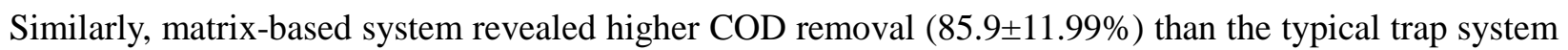
(60.4 $\pm 31.26 \%$ ). Characterizations of the influent, emulsified, adsorbed and effluent FOG indicated that straight saturated fatty acids (SSFA) constituted the cause of clogging problems in the FOG trap and piping system. 
ASCE Subject Headings: wastewater, wastewater treatment, biological treatment, oils

\section{INTRODUCTION}

The presence of fats, oils, and grease (FOG) in wastewater often results to significant problems in conventional mesophilic biological treatment systems. These problems are known to cause the formation of lipid films around the flocs due to the reduced oxygen transfer rate to the biomass (Becker et al., 1999;

Dueholm et al., 2000). Furthermore, this condition generates a favorable environment for the growth of the filamentous actinomycete, Nocardia amarae, which has been asserted to cause "scumming" and foaming in an activated sludge system (Becker et al., 1999; Madoni et.al., 2000). At the same time due to the reduction of the amount of excess sludge amenable to dewatering, lipid fermentation by the aforementioned actinomycete results in the release of aldehydes, ketones, and alcohols, all of which produce unpleasant odors (Canler et al., 2001).

FOG commonly present in wastewater can be characterized according to particle size--namely: free, dispersed, emulsified, and dissolved FOG (Lissant, 1974). Free and dispersed FOG can be removed by gravitational separation, whereas emulsified and dissolved FOG tend to rely more heavily on physicochemical and biological treatments. Current physico-chemical technologies, floatation and sedimentation in particular, have been proven insufficient, owing to problems encountered with sludge production when using flocculating agents, such as polyelectrolytes or salts. Furthermore, conventional physico-chemical 
FOG-trap designs have demonstrated serious disadvantages when soluble FOG is discharged into sewer systems. The accumulation of FOG in sewer pipes, pumps, and other equipment can restrict the flow of wastewater through a sanitary sewer collection system, eventually resulting to wastewater reflux into the facilities serviced by the respective pipes (Chao and Yang, 1981). Thus, emulsified and dissolved FOG still impose significant concerns, particularly in food processing industries and restaurants since its recovery is not feasible, as they are most often associated with the presence of fecal matter (Broughton et al., 1998). To alleviate treatment problems, pretreatment steps such as grease traps are installed to remove FOG from the wastewater prior to the main treatment process itself or to public sewers. As an effective option for FOG wastewater treatment, biological degradation by hydrolytic enzyme application has been recently reviewed (Cammarota and Freire, 2006).

To hydrolyze and dissolve fats at an accelerated period of time, enzyme application such as lipase is the most suitable option. However, a cost effective production is essential to this process. Solid state fermentation for enzyme production using agricultural wastes has been reported (Cammarota and Freire 2006). As an in situ application, passive whole cell immobilization on cheap matrices is a promising method of maintaining enzyme activity in order to preserve the pertinent biomass. It can provide higher enzyme activity yields after immobilization, better operational stability, greater resistance to environmental perturbations, and lower effective operational cost (Hermachander et al., 2001), as compared to conventional suspended growth systems (Loukidou and Zouboulis, 2001). Biofilm systems 
harboring lipolytic microorganisms could thereby improve FOG biodegradation via the introduction of potent lipase activity to the system. Lipase acts on the fatty acid chains of triglycerides at the lipid-water interface.

In this study, a newly isolated lipolytic strain, Pseudomonas aeruginosa D2D3, which has been registered as 10056BP (KCTC), was employed in a whole-cell immobilizing FOG trap system. This aerobic, bacillar, mesophilic bacterium, identified as a lipase- and biosurfactant-generating strain, has been reported previously (Shon et al., 2002). Our main goal is to investigate the feasibility of the cell immobilized trap system for FOG containing wastewater treatment. The system which is designed for the immobilization of the lipase-producing bacteria, Pseudomonas aeruginosa D2D3, was tested with a variety of matrices, and compared with a typical trap (without matrix) reactor with regard to chemical oxygen demand (COD) and FOG removal efficiencies.

\section{MATERIALS AND METHODS}

\section{Cell Immobilization and Matrices}

Soybean oil was utilized in this simulation, primarily due to its extensive use in Asian food establishments. The minimal salt medium (MSM), composed of the following: $4 \mathrm{~g}$ of sodium nitrate $\mathrm{NaNO}_{3} / \mathrm{L} ; 0.15 \mathrm{~g}$ of potassium dihydrogen phosphate $\mathrm{KH}_{2} \mathrm{PO}_{4} / \mathrm{L} ; 0.5 \mathrm{~g}$ of disodium hydrogen phosphate $\mathrm{Na}_{2} \mathrm{HPO}_{4} / \mathrm{L} ; 0.2 \mathrm{~g}$ of magnesium sulfate $\mathrm{MgSO}_{4} \cdot 7 \mathrm{H}_{2} \mathrm{O} / \mathrm{L} ; 0.0005 \mathrm{~g}$ of ferric chloride $\mathrm{FeCl}_{3} \cdot 6 \mathrm{H}_{2} \mathrm{O} / \mathrm{L}$, and 
$0.01 \mathrm{~g}$ of calcium chloride $\mathrm{CaCl}_{2} \cdot 2 \mathrm{H}_{2} \mathrm{O} / \mathrm{L}$, was dissolved in tap water, used and maintained at neutral $\mathrm{pH}$

(Moon et al., 2002; Shon et al., 2002). The MSM was used to provide minimum inorganic nutrient to

Pseudomonas aeruginosa D2D3 and the soybean oil was the sole carbon source in this study.

The matrices used were selected according to economic advantage, availability and adsorption capacity, the last being the primary basis for the selection. In the present study, the samples were allowed to equilibrate in simulated wastewater for 120 minutes and three materials with superior adsorption capacities (g oil adsorbed/g matrix) were chosen: rice bran (0.424), polyurethane (0.674), and ceramic beads (0.628). In theory, both polyurethane and ceramic exhibit hydrophobic characteristics which can enhance cellular affinity to the substrate adsorbed into the matrix, thereby improving the volumetric biodegradation rate of the substrates in a whole cell immobilized system as compared with suspended microbial system (Yamaguchi et al., 1999). Rice bran, an organic matrix, is rich in varied nutrient composition (13.5\% protein, 13.2\% FOG, 18.3\% carbohydrate, 38.3\% fiber, 7.8\% vitamin B and E and trace amounts of lipase). Given these favorable properties in addition to the criteria mentioned earlier, the selected materials are found to be suitable as matrices for a FOG trap system (Karel et al. 1985).

For each matrix, about 2L of enrichment medium with $10 \%$ of (v/v) Pseudomonas aeruginosa D2D3 ( $1 \mathrm{X} 10^{8} \mathrm{CFU} / \mathrm{ml}$ ) was allowed to circulate for $24 \mathrm{~h}$ in a bubble-column bioreactor. The matrices were loosely packed within a net for ease of collection after immobilization. Aeration was supplied through stone diffusers which generate micro bubbles. The immobilization technique involves the physical 
attachment of the microorganisms either on the surface or by entrapment within the pores of the matrices.

\section{Lab-Scale FOG-Trap}

A 6-L, 0.5-cm-thick, acrylic lab-scale FOG-trap system was divided into three chambers, each with a capacity of 2 liters as shown in Figure 1. Each chamber was equipped with aeration unit to provide adequate dissolved oxygen and to maintain contact between the microorganisms and FOG. In order to elucidate the flow regimes of bulk water and oil in the FOG trap system, red ink- and soy bean oil containing water were separately fed into the reactor. A typical HRT of 30 min for the grease trap system was adapted (Metcalf and Eddy, 1991). It was also reported that FOG removal efficiencies rapidly increased with increasing HRT up to $30 \mathrm{~min}$ and only slight differences were observed beyond this detention time (Chu and $\mathrm{Ng}, 2000$ ). When the red ink solution containing water was fed, it occupied the entire working volume of the system (dashed line in Figure 1) which indicated that water flowed naturally from chambers 1 to 3 . However, for soy bean oil containing water, oil phase was distinctly observed especially at the second chamber, wherein approximately more than 95\% was collected. This test confirmed the ability of the trap to physically separate FOG from the bulk wastewater.

Therefore, chamber 1 can serve as an equalization tank for the incoming FOG-containing wastewater.

Chamber 2 physically traps most of the FOG from wastewater as confirmed by a tracer test and chamber

3 takes up the residual emulsified FOG and trap microorganisms that would be washed away from 
previous chambers.

From matrix analysis, rice bran was found to contain lipase, hence was positioned in the first chamber in order to achieve the initial degradation of the entering FOG. The rice bran immobilized with Pseudomonas aeruginosa D2D3 was enclosed within a net in the upper portion of chamber 1 in a cylindrical baffle to maintain its contact with the flowing FOG wastewater. Since polyurethane matrix has the highest adsorption capacity, the immobilized polyurethane matrix with Pseudomonas aeruginosa D2D3 was packed into a perforated box near the surface of the water in chamber 2 where most of FOG is trapped. Due to mechanical and chemical stability, ceramic beads pre-immobilized with the same strain were housed at the third chamber. The ceramic beads also served as barriers that may separate the microorganisms from the effluent and minimize the discharge of high molecular weight biodegraded products (Allabashi, et.al, 2006).

Insert Figure 1.

The experiment was conducted for 16 days on each system to compare their performances. The simulated wastewater prepared in a 100-L tank was homogenized by mixing at $250 \mathrm{rpm}$. The wastewater was pumped through the FOG trap for 14 hours on each operation day. The FOG and COD removal efficiencies were monitored every day at the effluent stream with varied influent FOG concentrations of 200-10,000 mg/L. FOG height that accumulated in the second chamber of each system was also measured. 


\section{Full-Scale FOG-Trap}

A 600-L full-scale reactor was purchased from Zurn (PA, USA). It was installed at the O barbeque restaurant located nearby Myongji University at Yon gin City, Korea. The run-time operation of the fullscale FOG-trap system at a HRT of 30 min was initially conducted without matrices for 30 days, and then with the matrices for an additional month. The effluent samples were taken during peak hours of restaurant service.

\section{FOG Wastewater Characterization at Full-Scale Operation}

The food establishment $\mathrm{O}$ barbeque restaurant mainly serves pork and beef dishes. In one operation day, the maximum wastewater discharge takes place during peak service hours (i.e. lunch and dinner time). The wastewater being treated daily was measured to be approximately $7.93 \mathrm{~m}^{3} /$ day. The $\mathrm{pH}$ values were slightly acidic, owing primarily to the long chain fatty acid (LCFA) and volatile fatty acids (VFA) in the wastewater. The average BOD: N: P ratio was 100:0.04:0.005, indicating that $\mathrm{N}$ and $\mathrm{P}$ compounds may be insufficient for the biodegradation of the FOG-containing wastewater (Shon et al., 2002). The majority of the measured parameters, including COD, BOD, SS and FOG concentrations, were in excess of the discharge limits (HKEPD, 1991) as listed in Table 1. Thus, the installation of a FOG trap was deemed necessary for the $\mathrm{O}$ barbeque restaurant. The principal fatty acid components of the influent FOG, as shown in Table 2, were stearic, palmitic, oleic, and Alpha-linoleic acids, which is consistent with the fatty acid profile of vegetable oil, similar to those found in an urban wastewater (Lalman and Bagley 
2000).

Insert Table 1 and Table 2

\section{Analytical Techniques}

The total FOG concentrations were measured by partition-gravimetric method (No. 5520 B) adopted from The Standard Methods (APHA, 1998). Several parameters, including COD, TN, and TP, were analyzed using respective $\mathrm{Hach}^{\circledR}$ vials and spectrophotometer (HACH 2010). Suspended solids (mg SS/L) and $\mathrm{BOD}_{5}$ were evaluated according to standard methods (APHA, 1998), and $\mathrm{pH}$ was determined with a portable Thermo-Orion ${ }^{\circledR}$ probe (Model 250 series).

The degradation of FOG, as determined by the quantities of liberated free fatty acids, was assessed via the fatty acid methyl ester (FAME) method. The wastewater mixture was heated for 30 minutes in a boiling water bath in order to assist the liberation of the FOG from the sludge (which consisted of a strong and thick emulsion of FOG, water, and particulate matter). The FOG was then extracted with n-hexane by separatory funnels. Ten milliliters of saponification reagent (45g NaOH; $150 \mathrm{~mL}$ methanol, 150mL water) was added to the sample, vortexed, and then re-heated for 1 hour at $100^{\circ} \mathrm{C}$. After cooling, $10 \mathrm{~mL}$ of methylation reagent (325 ml 6.0M HCl; $275 \mathrm{ml}$ methanol) was added, vortexed, and re-heated for an additional 10 minutes at $80^{\circ} \mathrm{C}$, in order to allow the formation of methyl esters from the fatty acids. The FAMEs were extracted with $20 \mathrm{ml}$ of n-hexane. The extracted FAMEs were then analyzed using an HP 6890 plus gas chromatograph (Hewlett Packard) with flow ionization detector (FID) and HP Ultra-2 
capillary column (2.5\% phenyl methyl siloxane, $25 \mathrm{~m} \times 0.2 \mathrm{~mm})$. The GC unit was operated using hydrogen and air under controlled flow rates of 30 - and $400 \mathrm{ml} / \mathrm{min}$, respectively; the GC ramping temperature program initiated at $170^{\circ} \mathrm{C}$ followed by an increased of up to $260^{\circ} \mathrm{C}$ by $5^{\circ} \mathrm{C} / \mathrm{min}$ and up to final temperature of $310^{\circ} \mathrm{C}$ by $40^{\circ} \mathrm{C} / \mathrm{min}$; analytical run time lasted up to 20.75 minutes.

\section{Statistical Analysis}

In order to attain minimal deviations between the samples, five samples were collected hourly, beginning at the $10^{\text {th }}$ hour of operation on each day, and the average is represented as a daily value The standard deviation of each daily value for FOG and COD removal efficiencies is less than 5. For statistical comparison of the two systems in terms of removal efficiency, two-tailed t-test was performed at $95 \%$ confidence interval.

\section{RESULTS AND DISCUSSION}

\section{COD and FOG Removals at Lab-Scale Experiments}

Lab-scale experiments were performed in order to compare matrix-based to the typical trap system in terms of FOG and COD degradations with varying influent concentrations. Figure 2 illustrates the FOG removals of both systems at different initial FOG concentrations. Both systems accomplished very high FOG removal efficiencies (90-99.9\%). At influent FOG concentration of $\leq 1000 \mathrm{mg} / \mathrm{L}$, the difference in the performances of the two processes was not statistically significant $(t$-test, $p>0.05)$ although a gradual decrease of removal efficiency was observed in the typical trap. As the influent FOG concentration was 
increased to $\geq 5000 \mathrm{mg} / \mathrm{L}$, the matrix-based system achieved higher performance efficiency compared to the typical trap system $(\mathrm{p}=0.0006$ and 0.0058 at FOG concentration of 5000 and $10000 \mathrm{mg} / \mathrm{L}$, respectively).

In terms of the effluent FOG concentration, both systems demonstrated similar concentrations of for the first four days of operation at influent FOG concentration of $500 \mathrm{mg} / \mathrm{L}$ and less, indicating comparable performance between the two systems at the initial period of operation. However, the FOG effluent concentration gradually increased in the typical trap system as the influent concentration of FOG was increased to $1000 \mathrm{mg} / \mathrm{L}$. At influent FOG concentration of $\geq 5000 \mathrm{mg} / \mathrm{L}$, the treated effluent concentrations were not in compliance with the standard discharge limitation of $100 \mathrm{mg} / \mathrm{L}$ (HKEPD, 1991). On the contrary, a stable performance was observed in the matrix-based system with the FOG effluent concentrations below the discharge limit. Apparently, the matrix-based system was more effective for the treatment of high FOG concentration $(>1000 \mathrm{mg} / \mathrm{L})$ in order to comply with the FOG effluent standard.

Insert Figures 2

Above $85 \%$ of COD removal was achieved from both systems as shown in Figure 3. The removal efficiency of COD between the two systems was not statistically different during the first 10 days of operation ( $\mathrm{p}=1,0.667$ and 0.074 at influent FOG concentration of 500, 1000 and $5000 \mathrm{mg} / \mathrm{L}$, respectively). At influent FOG concentration of $10000 \mathrm{mg} / \mathrm{L}$, the COD removal efficiency was higher in 
matrix-based $(91.7 \pm 1.53 \%)$ than in a typical FOG trap $(85.3 \pm 0.58 \%)$, in which the difference was found significant $(p=0.03)$. However, it should be noted that two systems demonstrated significant difference $(p=0.003)$ in terms of COD removal attained during the last 3 days of operation even though the influent FOG concentration was the same as from days 8 to 10 . The matrix-based system achieved lower removal efficiency (85.3 $\pm 0.58 \%)$ compared to the typical trap system (92 $\pm 1.2 \%)$ from days 14 to 16 . In spite of this difference, the effluent COD concentrations of both systems were always below the effluent COD regulation limits.

The measured FOG heights at the surface of the second chamber of each system were shown in Figure 4. At influent FOG concentration of $\geq 1000 \mathrm{mg} / \mathrm{L}$, the FOG height trapped in the typical trap system increased along with increasing influent FOG concentration. On the other hand, the FOG heights in the the matrix-based system were considerably lower, and it started to increase after the $9^{\text {th }}$ operation day. It indicates that FOG might be removed mainly by matrix adsoprtion and biodegradation for the first 9 operation days, and by trap and biodegradation from the operational day 10 to 16 . Due to the continuous increase of FOG height at the matrix-based system, it was decided to reduce the influent FOG concentration back to $5000 \mathrm{mg} / \mathrm{L}$ in order to minimize the FOG accumulation. This was found effective as indicated by gradual decrease of FOG height due to biodegradation for the following operation days.

For better comparison between the two systems, FOG mass balance calculation was performed following the general equation below: 
Influent FOG (IF) = Effluent (E) + Accumulated (A) + Biodegradation (B) + Adsorbed on Matrix (Ad) (equation 1)

For a typical trap system, Ad and B are assumed to be zero which equate the FOG removal (IF-E) to A at the second chamber. Thus the amount of accumulated FOG can be quantified by performing a regression analysis between cumulative FOG removed by the typical trap and the accumulated FOG height at the second chamber for the entire 16 days of operation. From the results, the regression line follows a linear fit $(y=3358 x+185.6)$ with a correlation value $r^{2}=0.984$ wherein $y$ is the cumulative FOG removed, and $x$ is the FOG height, the constant value represents the amount of accumulated FOG (in g) that yields an immeasurable FOG height (near zero). This explains why no FOG height was measured at the first four days of operation for the typical trap system.

The obtained relation can be used to elucidate the FOG removal mechanism that governed in a matrixbased system. To assert that biodegradation in the matrix-based system did take place, a mass balance was performed by assuming that B is zero. The dotted line in Figure 4 was constructed to simulate the behavior of the matrix-based system when no biodegradation has taken place. The FOG heights were calculated using the same linear relationship but FOG adsorption of the matrix at the second chamber was accounted $(y=3358 x+185.6+145.67)$. From the constructed curve (dotted line), a FOG height in the matrix-based can be measured from day 6 which steadily increased similarly the typical trap until day 16. Occasionally, higher values were obtained and this may be attributed to the higher FOG removed in the matrix-based system than the typical trap. However, the FOG heights at the matrix-based are much lower. 
Therefore, the difference (FOG heights) between the matrix-based and dotted line from day 6 to 16 could be ascribed to the degree of biodegradation of FOG in the matrix-based system.

Based on cumulative results, the typical trap system was able to remove $97.4 \%$ of the total amount of FOGs that entered the system after 16 days due to accumulation in the chambers. On the other hand, 99.5\% was removed in the matrix-based system. About $93.6 \%$ of it was removed due to biodegradation, 1.4\% due to matrix adsorption and 5.0\% are accumulated in the second chamber of the matrix-based system.

Lower FOG heights measured in the matrix-based system indicates the high degradation of FOG by Pseudomonas aeruginosa D2D3 attached on the matrices. This can result in the increase of soluble COD due to release of degraded fatty acid (LCFA $\rightarrow$ short chain fatty acid) to the bulk solution in the system, which may possibly explain the higher effluent COD values at the last 3 days of operation in the matrixbased than in the typical trap. According to previous study of free fatty acid degradation in oil, the pathway of hexadecanoic and oleic acid degradation by Pseudomonas aeruginosa D2D3 were as follows: i) saturated fatty acid: hexadecanoic $(16: 0) \rightarrow$ triecanoic $(13: 0) \rightarrow$ dodecanoic $(12: 0) \rightarrow$ undecanoic $(11: 0) \rightarrow$ decanoic $(10: 0) \rightarrow$ short chain free fatty acid; ii) unsaturated fatty acid: oleic acid $(18: 1 \omega 9 c) \rightarrow$ cis-3-dodecen-1-ol (12:0 3OH) $\rightarrow$ cis-3-decen-1-ol (10:0 3OH) $\rightarrow$ 3-octanol (8:0 3OH) $\rightarrow$ short chain free fatty acid (Shon et al., 2002).

Insert Figures 3 and 4 


\section{Degradation of COD and FOG at the full-scale FOG-trap}

As shown in Figure 5, the performance of the typical trap system was very unstable and revealed average FOG and COD removal efficiencies of $74.6 \pm 27.13 \%$ and $60.4 \pm 31.26 \%$, respectively at the average influent concentrations of $463.4 \pm 296.86 \mathrm{mg}$ FOG/L and $3307.3 \pm 2120.99 \mathrm{mg}$ COD/L. The COD removal efficiency was much lower than FOG removal efficiency, owing to the presence of other soluble COD (about 85\% of the total COD) components aside from FOG. Effluent FOG concentrations exceed the discharge limits especially when inlet FOG was more than $300 \mathrm{mg} / \mathrm{L}$.

Insert Figure 5.

Matrix-based system performance in terms of FOG and COD removals was illustrated in Figure 6. The average FOG and COD removal efficiencies were $92.7 \pm 9.06 \%$ and $85.9 \pm 11.99 \%$ at the average influent concentrations of 1044.8 $\pm 537.27 \mathrm{mg}$ FOG/L and 5597.9 $\pm 3061.65 \mathrm{mg}$ COD/L, respectively. The performance of the matrix-based system was more stable than the typical trap system, as indicated by higher removal efficiency ( $\mathrm{p}=0.033$ and 0.013 for FOG and COD removal efficiency, respectively) even at higher influent FOG concentrations $(\mathrm{p}=0.016)$. Unlike lab-scale experiment, significantly lower FOG removal efficiency was observed in the typical trap system compared to the matrix-based system at influent FOG concentrations of $\leq 1000 \mathrm{mg} / \mathrm{L}$. According to Kochukunju et al. (2004), many genera produced lipase activity and Bacillus sp. was found to be one of predominant group that is ubiquitous in nature. Therefore it could be possibly stated that there might be potential synergy between Pseudomonas 
aeruginosa D2D3 immobilized on the matrices and mixed culture originated from the actual wastewater,

resulting in the enhancement of FOG removal. Further investigation is, however, required to provide biomolecular evidence for clear explanation of biodegradation. As compared with the typical trap system, the effluent concentrations of both FOG and COD were far lower than those in the regulation limit. These results clearly show the more effective performance of the matrix-based system over the typical trap system

Insert Figure 6.

\section{Determination of fatty acid compositions}

In order to determine the composition of the free fatty acids (FFAs), the FOG from the influent and effluent, as well as the emulsified FOG (EF) and solid form of adsorbed FOG (AF) in the $2^{\text {nd }}$ compartment of FOG trap of the matrix-based system were collected at the last day of operation. The total number of fatty acids detected in the influent, EF, AF and effluent were 97, 107, 94 and 80, respectively. Among all these fatty acids, Table 2 lists only 20 LCFAs containing carbon of $\geq 9$ which can be representative fatty acids detected in FOG. The four aforementioned FOG sources were identified as follows: straight and branched-chain saturated fatty acids (SSFA), monounsaturated fatty acids (MFA), polyunsaturated fatty acids (PFA), or monoenoic alcohols and aldehydes (MAA). The FOG obtained from the restaurant wastewaters harbored many MAA components, which are known to cause foul odors 
attributable to derivative matter generated by fermentation in the trap system, including aldehydes, alcohols, and ketones (Canler et al., 2001).

The main fatty acid component of FOG detected in the four sources were palmitic (C16:0), stearic (C18:0), oleic (C18:1 $\omega 9 \mathrm{c})$ and alpha linoleic $(\mathrm{C} 18: 2 \omega 6,9 \mathrm{c})$ acids. The structures of these acids tended more toward cis- than trans-chain conformations. These components are commonly found as general vegetable and animal FOG (Broughton et al., 1998; Casado et al., 1998). The saturated fatty acids, undecylic (C11:0) and nonadecylic (C19:0) acid, were not detected in any of the sources except for the adsorbed FOG located along the trap walls. No gamma linoleic acids were detected in the effluent and adsorbed FOG samples.

Based on the results in Table 2, the SSFA/MFA ratio of the influent, EF, AF and effluent were 0.51, 0.89, 0.86, and 0.53 respectively. The SSFA/PFA ratio for the influent, EF, AF and effluent were 0.62, 1.18, 1.43 , and 0.53 , respectively. Since majority of influent FOG $(\geq 95 \%)$ was collected in the $2^{\text {nd }}$ compartment of FOG trap system in the preliminary test of oil flow regime, it could be speculated that the increase of SSFA/MFA and SSFA/PFA in the $2^{\text {nd }}$ compartment compared to the influent could be evidence for biodegradation of unsaturated fatty acid. Polyunsaturated fatty acid was biodegraded much more rapidly than monounsaturated and saturated fatty acids (Grossi et al., 2001). These ratios also show that SSFA is one of main contributory factor for pipe clogging problem since the solid form of AF which can easily clog up the pipe contained higher portion of SSFA compared to the influent. 


\section{CONCLUSIONS}

The performance of a matrix-based FOG trap system inoculated with FOG-degrading bacteria

Pseudomonas aeruginosa was evaluated and compared with a typical trap system in terms of FOG and COD removal efficiencies, FOG accumulation and stability.

At lab-scale experiment, the two systems have comparable results in terms of COD and FOG removals at influent FOG $<1000 \mathrm{mg} / \mathrm{L}$. However, FOG removal at the matrix-based system became more effective when FOG concentration was increased $>1000 \mathrm{mg} / \mathrm{L}$, which might have resulted from the biodegradation and FOG adsorption within the matrices in the system. Furthermore, FOG accumulation in the typical trap system resulted in the increase of FOG height at the second chamber. Based on mass balance calculations, $97.4 \%$ of the total FOG load for 16 days was removed by a typical trap due to accumulation while $99.5 \%$ was removed by the matrix-based system, wherein about $93.6 \%$ removal is due to biodegradation, $1.4 \%$ due to matrix adsorption and 5.0\% due to accumulation. Thus, for long term operation, the typical trap system is more likely to encounter clogging problems than the matrix-based system. At full-scale operation, greater differences between the performances of the two systems were observed as revealed by higher overall removals of FOG and COD in the matrix-based system. In contrast to the lab-scale experiment result, the FOG removal was significantly higher in the matrix-based system than in the typical trap system even at influent FOG concentrations $\leq 1000 \mathrm{mg} / \mathrm{L}$. These results showed that the matrix-based system was more applicable to the actual FOG wastewater treatment and was able 
to sustain the required FOG and COD removals even at highly fluctuating influent concentrations.

\section{ACKNOWLEDGEMENT}

This research was funded by Biogreen 21, Rural Development Administration, Republic of Korea. (2002).

Project No. 20050401-034-750-142-01-00.

Dr. Ho Kyong Shon, PhD presently holds the Chancellor's postdoctoral fellowship at the Faculty of

Engineering, University of Technology, Sydney [P.O. Box 123, Broadway, NSW 2007, Australia. The

remaining authors, Grace M. Nisola, Dong Jun Chun, Dan Tian, Dr. Eulsaeng Cho, Dr. Eun Mi Gwon, and

Prof. Wook-Jin Chung are all members of the Department of Environmental Engineering and Biotechnology at Myong-Ji University [Yongin, 449-728, Korea]. 


\section{REFERENCES}

Allabashi, R., Arkas, M., Hormann, G., Tsiourvas, D. (2007). "Removal of some organic pollutants in water employing ceramic membranes impregnated with cross-linked silylated dendritic and cyclodextrin polymers.” Water Res., 41(2), 476-486.

APHA (1998). “Oil and Grease” Standard Methods for the Examination of Water and Wastewater, American Public Health Association, 20th edition, Washington, DC., 5-35 to 5-36.

Becker, P., Koster, D., Popov, M.N., Markossin, S., Antranikian, G., and Markl, H. (1999). "The Biodegradation of Olive Oil and the Treatment of Lipid-Rich Wool Scouring Wastewater Under Aerobic Thermophilic Conditions.” Water Res., 33(3), 653-660.

Broughton, M.J., Thiele, J.H., Birch, E.J., and Cohen, A. (1998). “Anaerobic Batch Digestion of Sheep Tallow.” Water Res., 32(5), 1423-1428.

Cammarota, M.C., Freire, D.M.G. (2006). “A Review on Hydrolytic Enzymes in the Treatment of Wastewater with High Oil and Grease Content.” Biores. Tech., 97(17), 2195-2210.

Canler, J.P., Royer, C., and Duchene, P. (2001). “Aerobic Biological Treatment of Grease from Urban Wastewater Treatment Plants.” Water Sci. and Technol., 44(2-3), 219-226. 
Chao, A.C. and Yang, W. (1981). "Biological Treatment of Wool Scouring Wastewater.” J. WPCF, 53, 311-317.

Casado, A.G., Hernandez, E.J.A., and Vilchez, J.L. (1998). "Determination of Fatty Acids $\left(\mathrm{C}_{8}-\mathrm{C}_{22}\right)$ in Urban Wastewater by GC-MS.” Water Res., 32(10), 3168-3172.

Chu, W. and Ng F.L. (2000). "Upgrading the Conventional Grease Trap Using a Tube Settler.” Environment Int., 26(1-2), 17-22.

Dueholm, T., Andreasen, K., and Nielsen, P. (2000). "Transformation of Lipids in Activated Sludge.” Water Sci.Technol., 43(1), 165-172.

Grossi, V., Blokker, P., and Sinninghe Damst J. (2001). “Anaerobic biodegradation of lipids of the marine microalga Nannochloropsis salina” Organic Geochem., 32, 795-808.

Hermachander, C., Bose, N., and Puvanakrishnan, R. (2001). "Whole Cell Immobilization on Ralstonia pickettii for Lipase Production.” Process Biochem., 36(7), 629-633.

HKEPD-Hong Kong Environmental protection Department. (1991). Technical Memorandum Standards for Effluents Discharging into Drainage and Sewerage Systems, Inland and Coastal Water. Hong Kong Government Printer, 15-26. 
Karel, S.F., Libicki, S.B., and Robertson, C.R. (1985). “The Immobilization of Whole Cells: Engineering Principles.” Chem. Eng. Sci., 40(8), 1321-1354.

Kochukunju, J., Nair, S., Chandramohan, D., Raveendran, O., and Nair, K.K.C. (2004). "Fatty acid profiles: Comparison of lipase and non-lipase producing Bacillus sp. Isolated from marine organisms in the Cochin Backwaters.” Conference on Microbiology of the Tropical Seas, National Institute of Oceanography, Dona Paula, Goa (403 004), India, 13-15, Dec., 2004.

Lalman, J.A. and Bagley, D.M. (2000). “Anaerobic Degradation and Inhibitory Effects of Linoleic Acid.” Water Res., 34(17), 4220-4228.

Lissant, K. J. (1974). Emulsions and Emulsion Technology Part I. Marcel Dekker Inc., I: 3-10.

Loukidou, M.X. and Zouboulis, A.I. (2001). “Comparison of Two Biological Treatment Processes Using Attached Growth Biomass for Sanitary Landfill Leachate Treatment.” Environ. Poll., 111(2), 273-281.

Madoni, P., Davoli, D., and Gibin, G. (2000). "Survey of Filamentous Microorganisms from Bulking and Foaming Activated Sludge Plants in Plants in Italy.” Water Res., 34(6), 1767-1772.

Metcalf and Eddy (1991). Wastewater Engineering, Treatment, Disposal and Reuse. $3^{\text {rd }}$ edition. MacGraw-Hill, Inc., 1991. pp. 1028-1029. 
Moon, H.J., Lim, Y.K., Kim, H.S., Kwon, D.Y., and Chung, Wook-Jin (2002). "Glycolipid biosurfactants produced by Pseudomonas aeruginosa D2D2 from diesel - contaminated soil.” J. Microbiol. Biotechnol., 12(3), 371-376.

Shon, H.K., Tian, D., Kwon, E.M., Jin, C.S., Lee, T.J., and Chung, W.J. (2002). “Degradation of Fat. Oil, and Grease (FOG) by Lipase-Producing Bacterium Pseudomonas sp. Strain D2D3.” J. Microbiol. Biotechnol., 12(4), 583-591.

Yamaguchi, T., Ishida, M., and Suzuki, T. (1999). "Immobilized Cell System in Polyurethane Foam for the Lipophilic Micro-Alga Prototheca zopfii.” Process Biochem., 34(2), 167-171. 


\section{List of Tables and Figures:}

Tables

Table 1. Average influent wastewater characteristics from the $\mathrm{O}$ barbecue restaurant.

Table 2. Free fatty acid compositions of influent, EF, AF and effluent regions of the FOG trap system installed at the O barbecue restaurant.

\section{Figures}

Figure 1. Schematic diagram of the operated FOG-trap system for lab- and full-scale operations (A: rice bran matrix [3\% v/v]; B: polyurethane $[15 \% \mathrm{v} / \mathrm{v}]$, C: ceramic [ $40 \% \mathrm{v} / \mathrm{v}]$ ) Aeration rate: $2 \mathrm{~L} / \mathrm{min}$. Figure 2. FOG removals in a 6-liter lab-scale experiment of matrix-based and typical FOG trap systems (Operation: 14 hrs/run).

Figure 3. COD removals in a 6-liter lab-scale experiment of matrix-based and typical FOG trap systems (Operation: 14 hrs/run).

Figure 4. FOG height accumulated at 2nd chamber of lab-scale FOG trap with matrix-based and typical system.

Figure 5. Performance of full-scale typical FOG-trap system without matrices in terms of (A) FOG- and (B) COD removals.

Figure 6. Performance of full-scale immobilized matrix-based FOG-trap (600L) system in terms of (A) FOG- and (B) COD removals. 
Table 1. Average influent wastewater characteristics from the O barbecue restaurant.

\begin{tabular}{clcc}
\hline \multicolumn{2}{c}{ Parameters } & Influent & Standard \\
\hline BOD & $(\mathrm{mg} / \mathrm{L})$ & $3097 \pm 25.3$ & 1200 \\
COD & $(\mathrm{mg} / \mathrm{L})$ & $4280 \pm 50.7$ & 3000 \\
FOG & $(\mathrm{mg} / \mathrm{L})$ & $894 \pm 37.1$ & 100 \\
Temp. & $\left({ }^{\mathrm{O}}\right)$ & $15.6 \pm 0.3$ & 43 \\
TN & $(\mathrm{mg} / \mathrm{L})$ & $121.1 \pm 3.1$ & 200 \\
TP & $(\mathrm{mg} / \mathrm{L})$ & $16.2 \pm 0.4$ & 50 \\
pH & & $6.9 \pm 0.5$ & $2-8$ \\
Salinity & $(\%)$ & $0.67 \pm 0.1$ & - \\
SS & $(\mathrm{mg} / \mathrm{L})$ & $1260.4 \pm 61.0$ & 1200 \\
\hline
\end{tabular}


Table 2. Free fatty acid compositions of influent, EF, AF and effluent regions of the FOG trap system installed at the $\mathrm{O}$ barbecue restaurant.

\begin{tabular}{|c|c|c|c|c|c|}
\hline $\begin{array}{l}\text { Type of Fatty Acids } \\
\text { (FAs) }\end{array}$ & Name & Influent (\%) & Effluent (\%) & $\mathrm{EF}(\%)$ & $\mathrm{AF}(\%)$ \\
\hline \multirow{11}{*}{ SSFA } & Pelagonic $\left(\mathrm{C}_{9: 0}\right)$ & 0.04 & 0.04 & 0.14 & 2.41 \\
\hline & Capric $\left(\mathrm{C}_{10: 0}\right)$ & 0.1 & 0.23 & 0.16 & 0.17 \\
\hline & Undecylic $\left(\mathrm{C}_{11: 0}\right)$ & ND & ND & ND & 0.01 \\
\hline & Lauric $\left(\mathrm{C}_{12: 0}\right)$ & 0.58 & 1.47 & 1.31 & 0.28 \\
\hline & Myristic $\left(\mathrm{C}_{14: 0}\right)$ & 0.56 & 0.92 & 1.24 & 1.17 \\
\hline & Pentadecylic $\left(\mathrm{C}_{15: 0}\right)$ & 0.02 & 0.04 & 0.04 & 0.04 \\
\hline & Palmitic $\left(\mathrm{C}_{16: 0}\right)$ & 7.68 & 11.2 & 11.33 & 13.4 \\
\hline & Margaric $\left(\mathrm{C}_{17: 0}\right)$ & 1.06 & 0.35 & 1.1 & 0.14 \\
\hline & Stearic $\left(\mathrm{C}_{18: 0}\right)$ & 4.71 & 3.79 & 6.4 & 6.09 \\
\hline & Nonadecylic $\left(\mathrm{C}_{19: 0}\right)$ & ND & ND & ND & 1.67 \\
\hline & Arachidic $\left(\mathrm{C}_{20: 0}\right)$ & 0.17 & 0.22 & 0.39 & 0.21 \\
\hline \multirow{7}{*}{ MFA } & Physeteric $\left(\mathrm{C}_{14: 1 \omega 9 \mathrm{c}}\right)$ & ND & 0.09 & 0.04 & 0.04 \\
\hline & cis-9-pentadecenoic* $\left(\mathrm{C}_{15: 1 \omega 6 c}\right)$ & ND & ND & 0.07 & ND \\
\hline & Palmitoleic $\left(\mathrm{C}_{16: 1 \omega 7 \mathrm{c}}\right)$ & 0.73 & 1.08 & 1.1 & 1.52 \\
\hline & cis-9-heptadecenoic* $\left(\mathrm{C}_{17: 1 \text { w8c }}\right)$ & 3.12 & 2.53 & 1.63 & 0.72 \\
\hline & Oleic $\left(\mathrm{C}_{18: 1 \omega 9 \mathrm{c}}\right)$ & 22.78 & 30.42 & 21.11 & 25.38 \\
\hline & cis-13-nonadecenoic* $\left(\mathrm{C}_{19: 1 \text { w6c }}\right)$ & 2.56 & 0.04 & 0.56 & 1.69 \\
\hline & Gondoic $\left(\mathrm{C}_{20: 1 \omega 9 \mathrm{c}}\right)$ & 0.28 & 0.39 & 0.42 & 0.42 \\
\hline \multirow{2}{*}{ PFA } & Alpha linoleic $\left(\mathrm{C}_{18: 2 \omega 6,9 \mathrm{c}}\right)$ & 20.92 & 34.6 & 14.77 & 17.91 \\
\hline & Gamma linoleic $\left(\mathrm{C}_{18: 3 \omega 6,9,12 \mathrm{c}}\right)$ & 3.29 & ND & 3.91 & ND \\
\hline Other minor FFAs & (60-80 minor FAs) & 31.40 & 12.59 & 34.28 & 26.73 \\
\hline
\end{tabular}




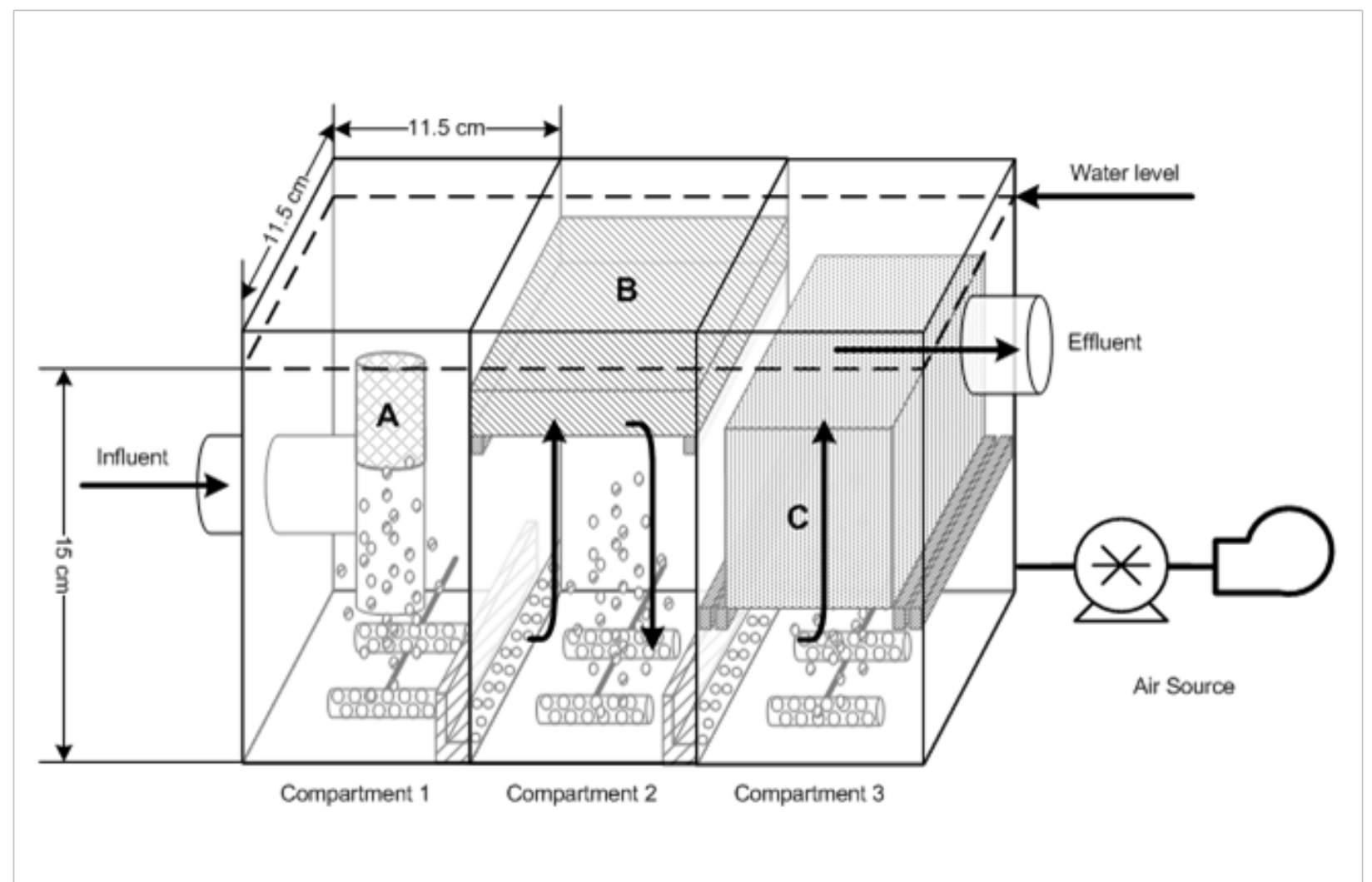

Figure 1. Schematic diagram of the operated FOG-trap system for lab- and full-scale operations (A: rice bran matrix [3\% v/v]; B: polyurethane $[15 \% \mathrm{v} / \mathrm{v}]$, C: ceramic [40\% v/v]) Aeration rate: $2 \mathrm{~L} / \mathrm{min}$. 


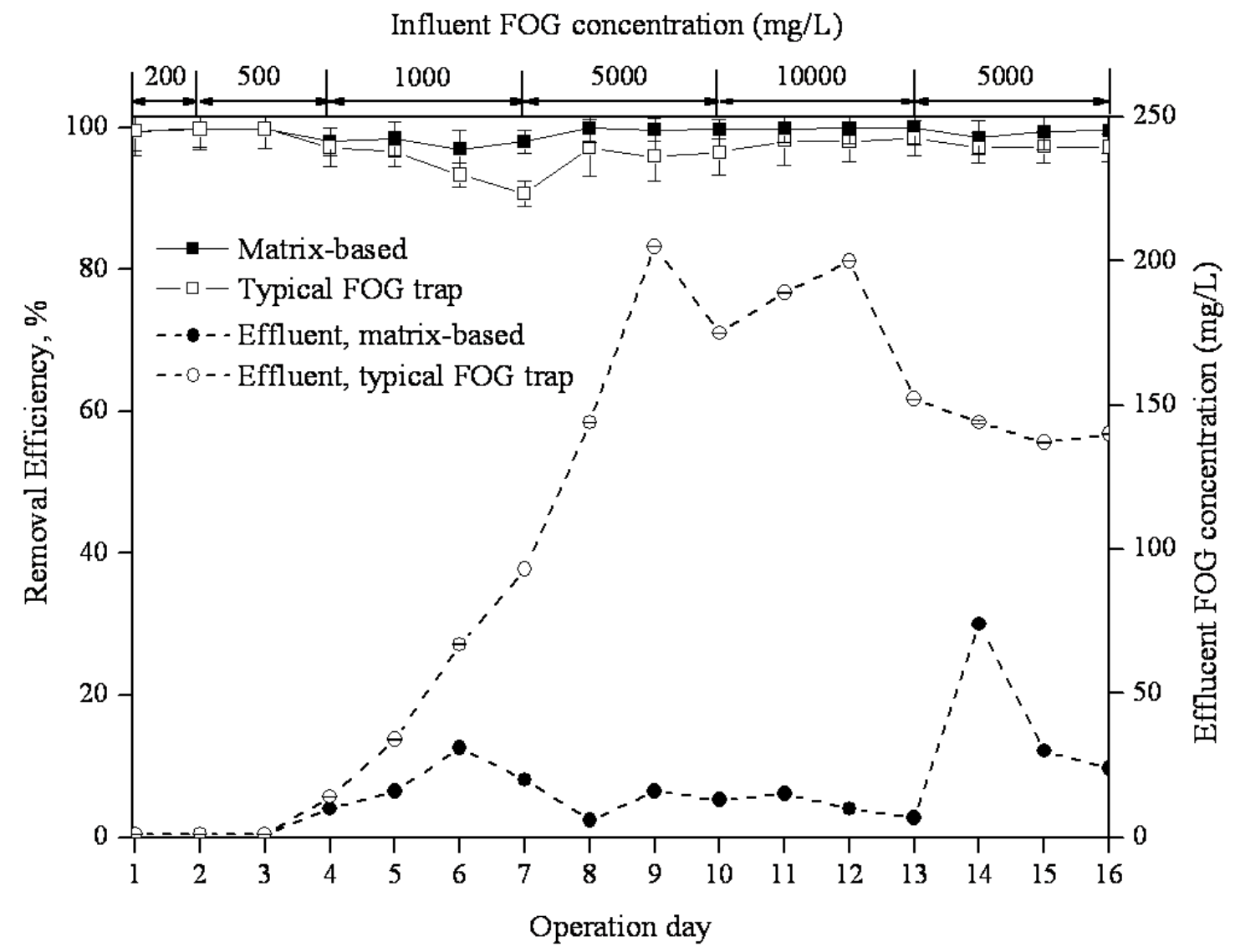

Figure 2. FOG removals in a 6-liter lab-scale experiment of matrix-based and typical FOG trap systems (Operation: 14 hrs/run). 


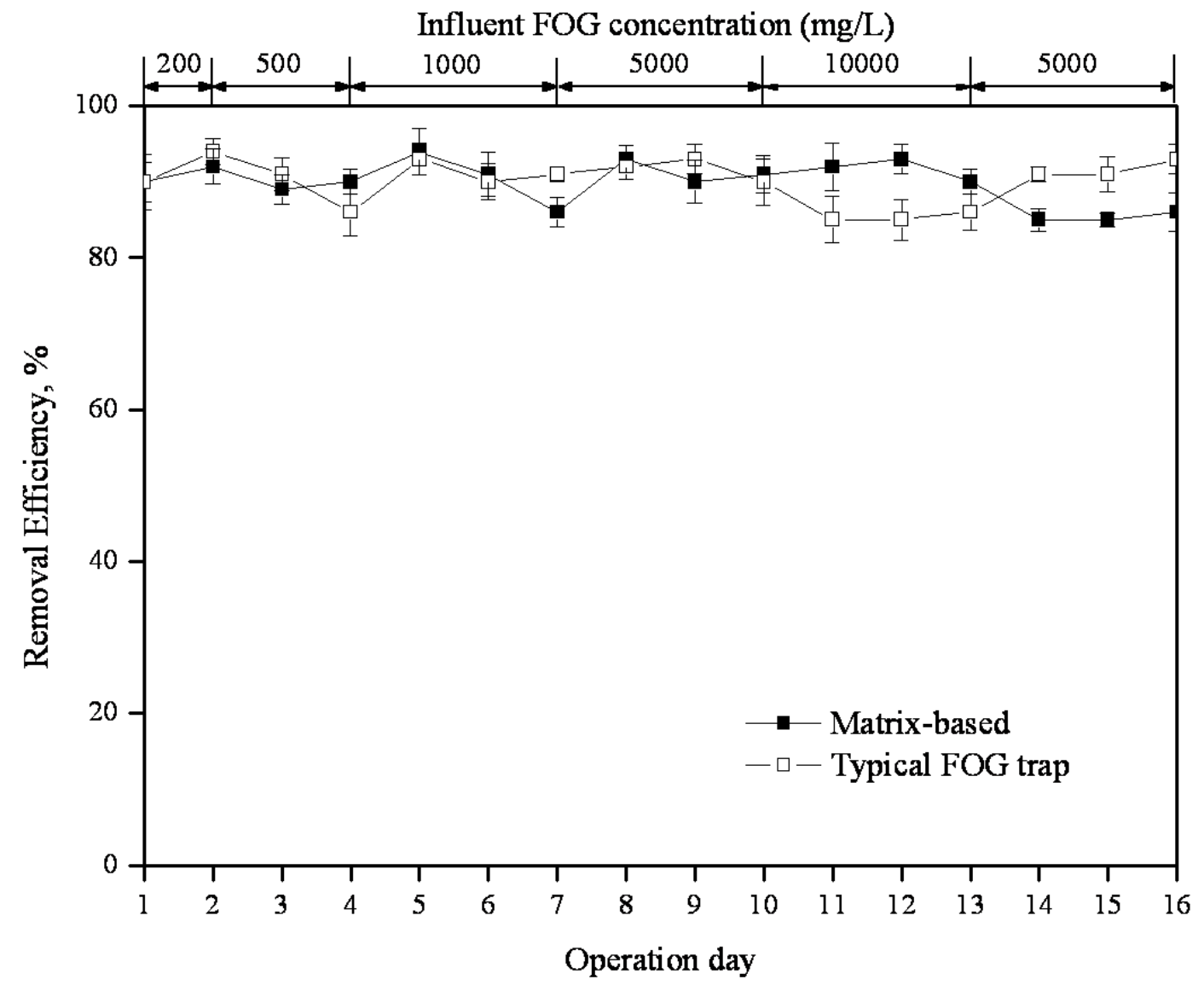

Figure 3. COD removals in a 6-liter lab-scale experiment of matrix-based and typical FOG trap systems (Operation: 14 hrs/run). 


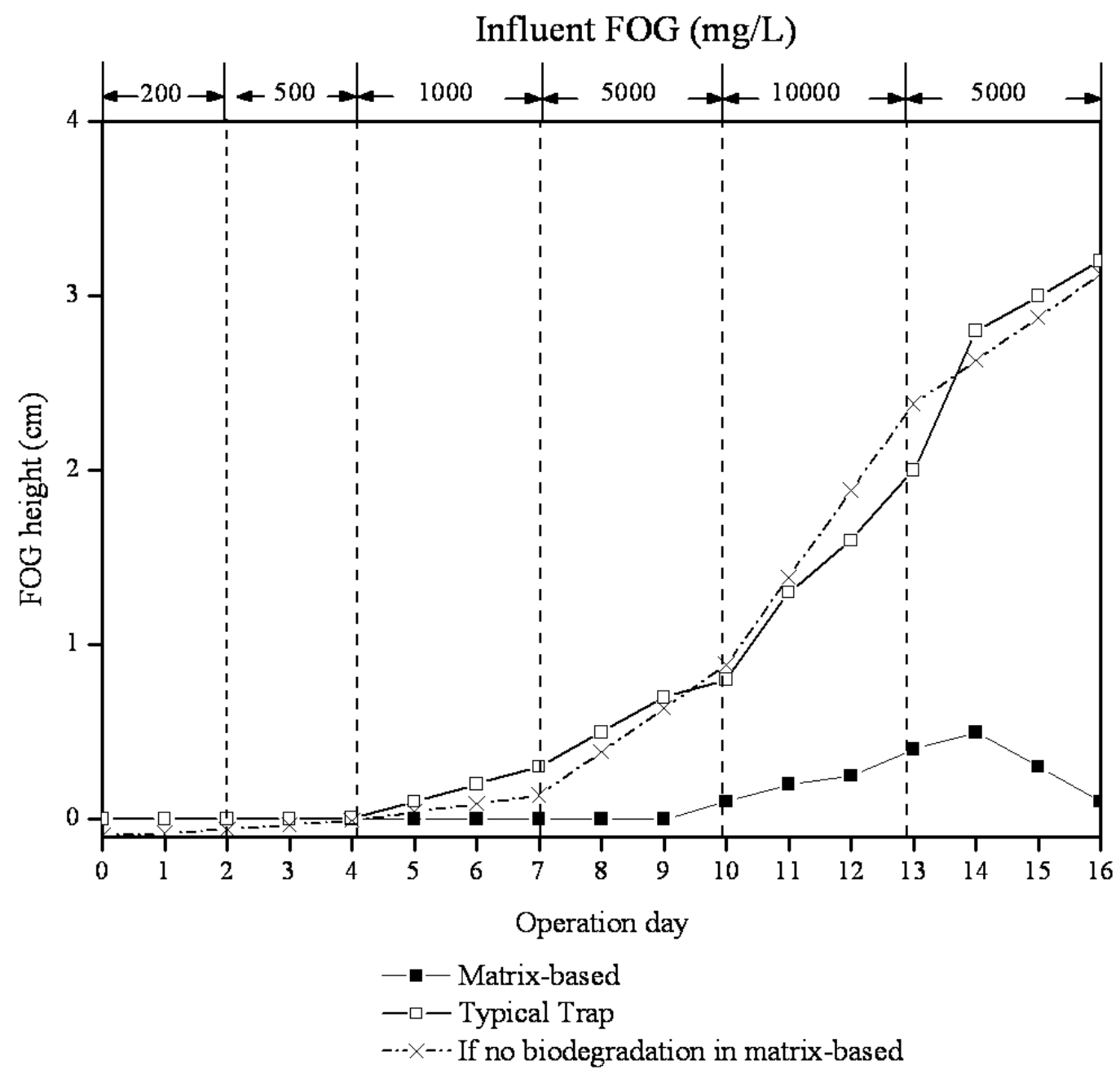

Figure 4. FOG height accumulated at 2nd chamber of lab-scale FOG trap with matrix-based and typical system. 

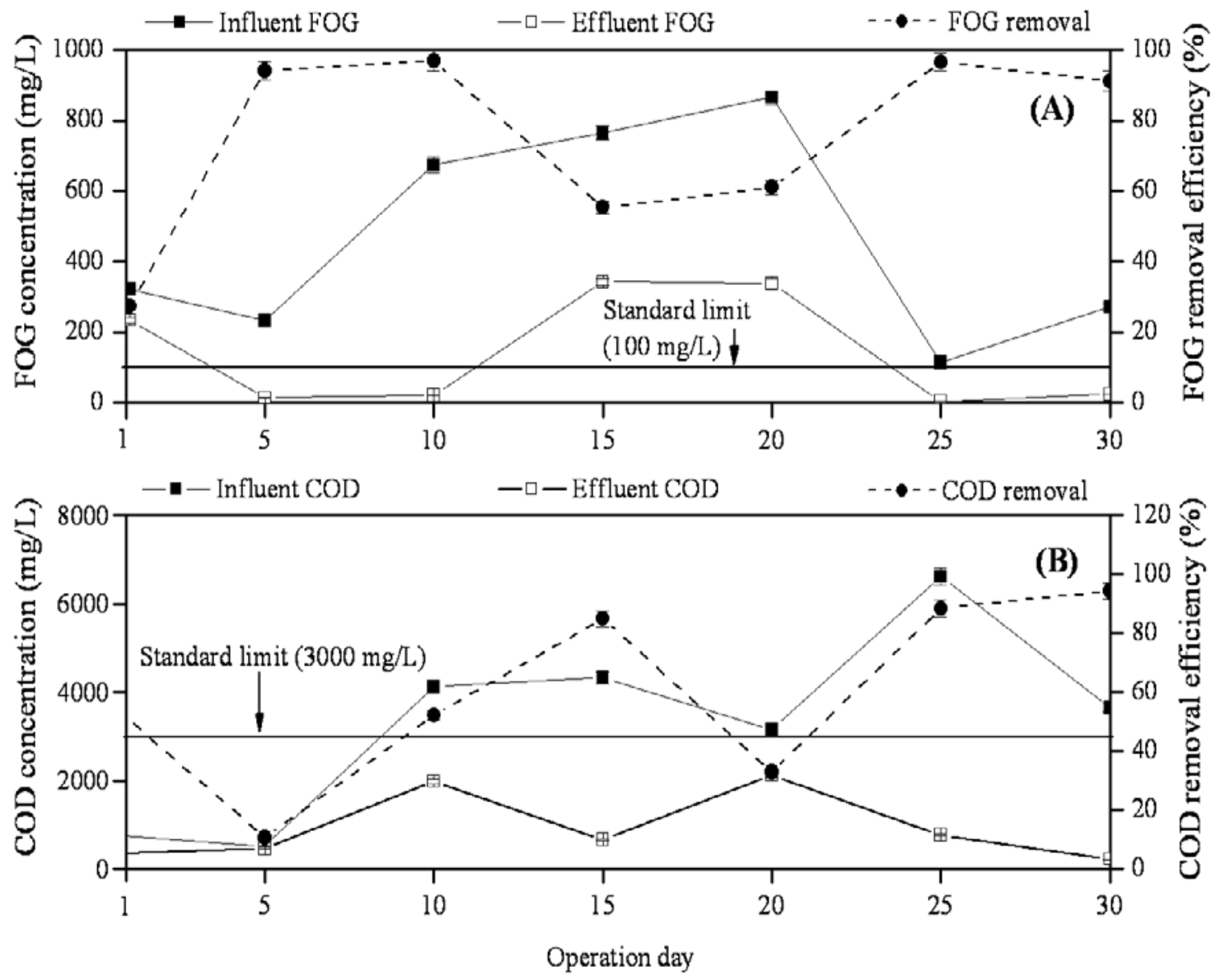

Figure 5. Performance of full-scale typical FOG-trap system without matrices in terms of (A) FOG- and (B) COD removals. 

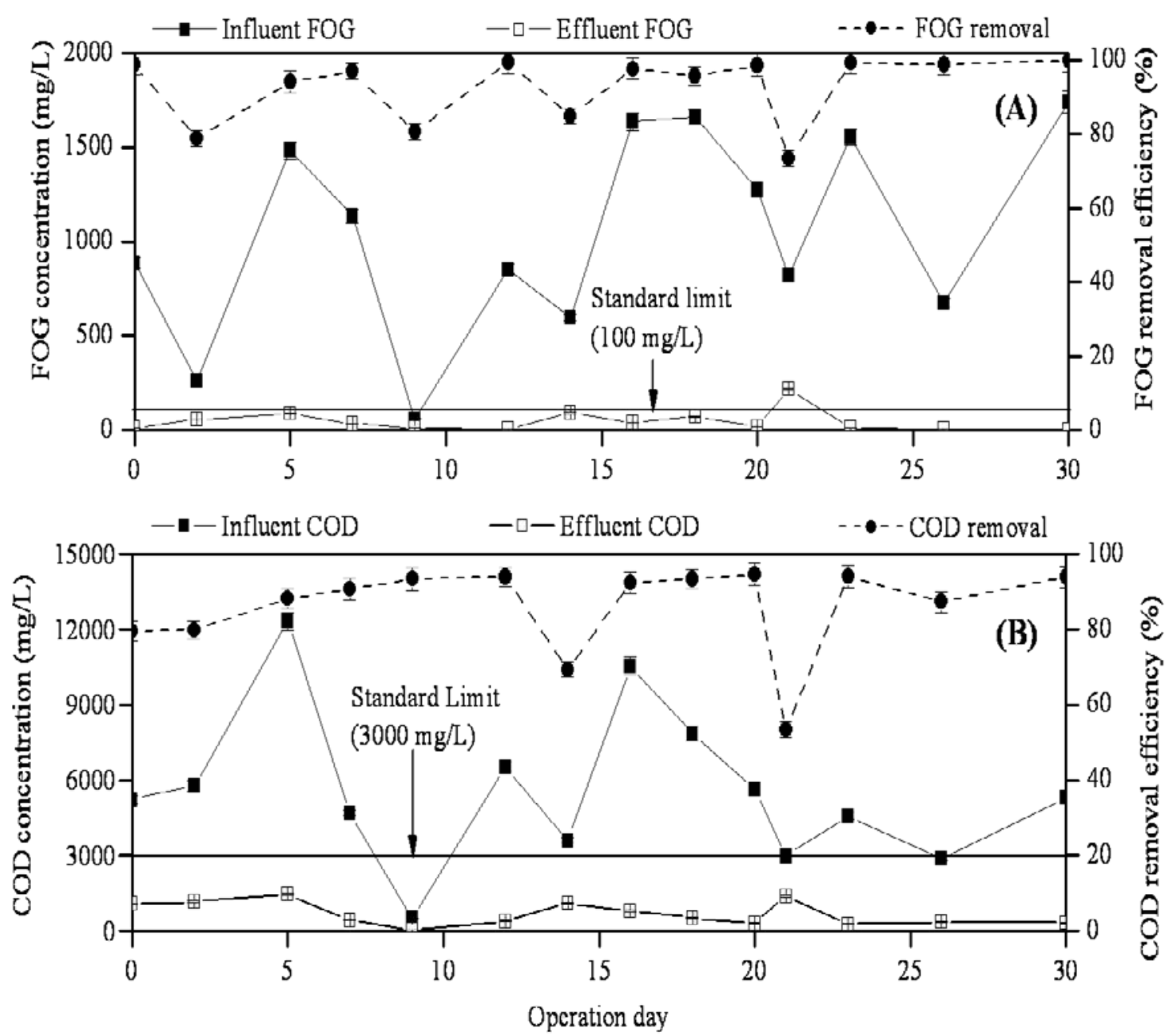

Figure 6. Performance of full-scale immobilized matrix-based FOG-trap (600L) system in terms of (A)

FOG- and (B) COD removals. 